\title{
Monte Carlo simulations of radiative heat exchange in a street canyon with trees
}

Zhi-Hua Wang* $^{*}$

School of Sustainable Engineering and the Built Environment, Arizona State University

Tempe, AZ 85287, USA

*Email: zhwang@asu.edu. Tel: +1-480-727-2933; Fax: +1-480-965-0557 


\section{Abstract}

Land surface energy balance in a built environment is widely modelled using urban

3 canopy models with representation of building arrays as a big street canyon. Modification

4 of this simplified geometric representation, on the other hand, leads to challenging

5 numerical difficulties in improving physical parameterization schemes that are

6 deterministic in nature. In this paper, we develop a stochastic algorithm to estimate view

7 factors between canyon facets in the presence of shade trees based on Monte Carlo

8 simulation, where an analytical formulation is inhibited by the complex geometry. The

9 model is validated against analytical solutions of benchmark radiative problems as well as

10 field measurements in real street canyons. In conjunction with the matrix method resolving

11 infinite number of reflections, the proposed model is capable of predicting the radiative

12 exchange inside the street canyon with good accuracy. Modeling of transient evolution of

13 thermal filed inside the street canyon using the proposed method demonstrate the potential

14 of shade trees in mitigating canyon surface temperatures as well as saving of building

15 energy use. This new numerical framework also deepens our insight into the fundamental

16 physics of radiative heat transfer and surface energy balance for urban climate modeling.

18 Keywords: Building energy consumption; Monte Carlo method; Radiative heat transfer;

19 View factors 


\section{1. Introduction}

Today, urban areas are home to more than half of the world's population, with a

23 projected urban population of 6.3 billion (68\% total global population) in 2050 (United

24 Nations, 2012). Complex landscape characteristics presented in a built environment has led

25 to significant modification of surface partitioning of solar energy. Urban areas therefore

26 have higher environmental temperatures than their rural surroundings, a well-known

27 phenomenon as the "urban heat island” (UHI) (Oke, 1982; Taha, 1997; Arnfield, 2003). As

28 a consequence, urban climate, as largely dictated by functions of manmade infrastructure

29 and human stressors, has paramount effect on energy consumption in cities (Santamouris et

30 al., 2001; Kikegawa et al., 2003). The past decade has seen increasing effort in reducing

31 the impact of UHI on energy use with various mitigation strategies such as the use of cool

32 pavements, green roofs, and shade trees (Akbari et al., 2001; Ouldboukhitine et al., 2014;

33 Santamouris, 2014). Understanding the fundamental physics governing the working

34 mechanisms of these strategies, especially on how they change the surface energy balance

35 in urban canopies, is becoming increasingly pressing to researchers.

In addition to thermal and optical properties of pavement materials (Sailor et al.,

37 2006; Synnefa et al., 2007), urban morphology plays a critical role in dictating UHI

38 intensity and has a significant impact on building energy consumption (Wong et al., 2011).

39 In particular, the geometry and density of building arrays are important contributors to the

40 surface energy balance of built environments through radiative trapping and shading

41 effects (Harman et al., 2004; Wang et al., 2011b). Radiosity algorithms have been

42 developed to predict surface irradiance and interior illumination in urban environments

43 (Robinson and Stone, 2005; 2006). Contributions of radiance from discretized patches, 
44 partially obscured by the canyon geometry and presence of obstructions, are predicted 45 using ray-tracing methods, and the associated view factors can be estimated. Radiosity 46 methods exhibit good accuracy in predicting radiative transfer at building-revolving scales 47 (with spatial resolutions $<10 \mathrm{~km}$ ), as compared to other radiation models (Robinson and 48 Stone, 2004).

This study, on the other hand, focuses on the development of a radiative transfer 50 model in urban canopies that will later be incorporated into numerical weather predictions

51 of urban areas at city scales (with spatial resolutions $\sim 10-100 \mathrm{~km}$ ). At these large scales, 52 numerical urban land surface models do not resolve detailed building and street canyon 53 geometries, but rather resort to simplified representations. Currently, two broad types of 54 representations of a "generic" urban area are adopted, viz. as a two dimensional (2D) street 55 canyon (Nunez and Oke, 1976), or a three dimensional (3D) rectangular block (Aoyagi and 56 Takahash, 2012). With these simplified geometric representations, building arrays are 57 usually resolved by normalized roof, wall and road dimensions for 2D canyons (Kusaka et 58 al., 2001), or by roof and frontal areas for 3D blocks (Grimmond and Oke, 1999). 59 Currently, most urban surface energy models are based on the 2D street canyon 60 representation of urban areas, e.g. the urban canopy models (UCM) adopted in the widely61 used Weather Research and Forecasting (WRF) platform (Chen et al., 2011). With this 62 geometric simplification, radiative heat exchange in urban areas can be analytically 63 resolved based on the view factors among urban facets (sky, ground, and walls). While the 64 2D street canyon representation of a built terrain is attractive due to its geometric 65 simplicity, any incremental modification to the geometry can lead to laborious effort or 66 even formidable challenges in modifying physical parameterizations of UCMs. 
Of particular importance to this study, recent advances in urban climate modeling demonstrate that it is critical to include urban vegetation and the associated hydrological processes for UCMs to realistically capture the surface energy budgets, especially the latent heat (Grimmond et al., 2010, 2011). This requirement has led to new urban parameterization schemes that integrate urban vegetation, grass or trees, in street canyons to enable direct soil-vegetation-atmosphere interactions (Lemonsu et al., 2012; Wang et al., 2013). On the other hand, these changes necessarily bring up new modeling challenges, such as how the shading effect of trees in a street canyon can be realistically represented? Analytical formulation of view factors with the presence of trees in a street canyon will be extremely difficult, if not impossible, given a variety of geometry of trees, needless to mention their spatial locations and sizes. In addition, degraded air quality in urban areas can modify the optical and radiative properties in the canopy layer (Prabhakar et al., 2014) and challenge the assumption of air as a non-participating (transparent, non-scattering, and non-absorbing) medium for radiative transfer in urban areas. This is particularly concerned for cities with severe pollution, e.g. heavy PM 2.5, PM 10 and aerosol loads in megacities in northern China (Sun et al., 2006; Li et al., 2007).

To address these new challenges, one naturally resorts to stochastic approaches based on random sampling, e.g. a Monte Carlo method. Monte Carlo simulations of radiative heat transfer have a long history of development (Howell, 1968, 1998; Yang et al. 1995). While its advantage may not be obvious for problems with simple geometries and ideal transmitting media, Monte Carlo is an excellent technique for modeling complex terrains and anthropogenic sources of emissions presented in highly urbanized environments. The main advantage of Monte Carlo is that when the problem complexity increases, the 
numerical expense of analytical methods involving mathematical integration of radiative

91 transport equation increases exponentially, while that of Monte Carlo procedures only

92 increases linearly (Howell, 1968). In the literature, only a handful number of Monte Carlo

93 methods were available for radiative heat transfer in street canyons. The most recent model

94 by Krayenhoff et al. (2014) is probably the only one that takes into account the presence of

95 trees in urban canopies. However, their work was developed for a multi-layer UCM with

96 probabilistic distribution of building heights, and there was a lack of comparison to field

97 measurements.

98 In this paper, we derive a Monte Carlo algorithm for radiative exchange in 2D street

99 canyons, incorporating the presence of trees (or generic obstacles alike) and their shading

100 effect. In combination with matrix method for infinite radiative reflections as well as

101 analytical method for heat conduction through the building envelope, a new modeling

102 framework is developed for capturing energy balance inside a street canyon with realistic

103 representation of radiative exchange based on stochastic procedures. The proposed method

104 is validated against benchmark radiative transfer problems using analytical method, as well

105 as in-situ measurements in urban areas. The validated model is then applied to study the

106 effect of various canyon and tree geometries on the radiative exchange in a street canyon.

107 Shading effect of trees lead to reduced surface temperature of canyon facets (walls and 108 roads), as well as potential saving of building energy.

109 The proposed method for radiative exchange is developed for a simplified 2D "big 110 canyon” with particular applications to numerical weather prediction of urban areas at 111 large (neighborhood to city) scales, via incorporation into the widely used WRF-UCM 112 platform. With improved model accuracy of resolving radiative heat fluxes as well as 
113 surface temperatures at each canyon facet, the proposed method will enhance the

114 predictability of the overall numerical framework on other surface energy budgets, viz.

115 sensible and latent heat and thermal storage in built environments. Future development and

116 applications of this numerical framework will also help to provide useful guidelines for

117 urban landscape management and sustainable urban planning in terms of, e.g. solar energy

118 harvest, heat island mitigation, and/or building energy efficiency.

119

$120 \quad$ 2. Model algorithms

121 In this section, we present the detailed algorithms and formulation of the proposed

122 numerical framework, including the Monte Carlo method for estimating view factors in a 123 street canyon with shade trees, and the matrix inversion for resolution of infinite

124 reflections among canyon facets. Note that the proposed method is developed for longwave 125 (diffuse) thermal radiation, which is appropriate for street canyons with direct solar 126 irradiance shaded by obstructions and trees.

127

\section{2.1. Monte Carlo method for radiative view factors}

129 Consider an energy bundle (radiative "ray”) between two generic surfaces, as shown 130 in Fig. 1, emitting from surface 1 and received by surface 2. The radiative view factors $F_{12}$, 131 with a ray radiated from a generic area $A_{1}$ and incident on another generic area $A_{2}$, is given 132 by,

$$
F_{12}=\frac{1}{A_{1}} \int_{A_{1}} \int_{A_{2}} \frac{\cos \eta_{1} \cos \eta_{2}}{\pi S^{2}} d A_{2} d A_{1}
$$


134 where $\eta_{1}$ and $\eta_{2}$ are the angle between the ray and the surface normal of $A_{1}$ and $A_{2}$, 135 respectively; and $S$ is the path length of the ray. Properties that must be satisfied by view 136 factors matrix include: self-view factor for a flat facet must be zero, and no radiant energy 137 can be lost, i.e.

$$
F_{i i}=0 \text {, no summation over } i ; \sum_{j=1}^{N} F_{i j}=1 \text {. }
$$

139 In addition, the reciprocal relation holds, i.e.

$$
A_{1} F_{12}=A_{2} F_{21} \text {. }
$$

In particular, the view factors between the four urban facets of the $2 \mathrm{D}$ street canyon (the "sky", two walls, and the road, without trees) can be solved by analytical integration, and are given by (Sparrow and Cess, 1978)

$$
F_{S G}=F_{G S}=\sqrt{1+\left(\frac{H}{W}\right)^{2}}-\frac{H}{W},
$$

$$
F_{W W}=\sqrt{1+\left(\frac{W}{H}\right)^{2}}-\frac{W}{H},
$$

$$
\begin{gathered}
F_{S W}=F_{G W}=\frac{1}{2}\left[1-\sqrt{1+\left(\frac{H}{W}\right)^{2}}+\frac{H}{W}\right], \\
F_{W S}=F_{W G}=\frac{1}{2}\left[1-\sqrt{1+\left(\frac{W}{H}\right)^{2}}+\frac{W}{H}\right],
\end{gathered}
$$

148 where subscripts $S, G$, and $W$ denote sky, ground, and wall, respectively, $H$ is the building 149 height, and $W$ is the width of canyon, as shown in Figure 2.

It is straightforward to verify that the analytical formulas observe the properties of 151 view factors in Eqs. (2)-(3). Analytical formulas of view factors, such as Eqs. (4)-(7), are 
152 handy to use but may become difficult to formulate in more complex problems. For 153 example, analytical computation of view factors for a street canyon with trees, as shown in 154 Figure 2, is hitherto absent (Krayenhoff et al., 2014). The Monte Carlo method, on the 155 other hand, invokes a probabilistic sampling of all rays emitted from surface by taking a 156 "random walk", and avoids the difficulty inherent in the integration process of Eq. (1) for 157 complex geometry (Howell, 1968). To randomize the radiative exchange process, the 158 direction of the emitted bundle can be determined by the polar angle $\theta_{1}$ and the azimuthal 159 angle $\eta_{1}$, each associated with a random number $R_{\theta}$ and $R_{\eta}$ as:

$$
R_{\theta}=\frac{\theta_{1}}{2 \pi}
$$

The emitting coordinates of all four canyon facets of a 2D street canyon, are given by

$$
x_{e}=W R_{x} ; \quad z_{e}=H R_{z},
$$

164 where $R_{x}$ and $R_{\mathrm{z}}$ are the random numbers associated with emitting coordinates $x_{e}$ and $z_{e}$ 165 from a given canyon facet in $x$ and $z$ directions, respectively, $W$ the canyon width, and $H$ 166 the wall height. To track the incident location of a ray transfer between two parallel 167 surfaces, only one coordinate will be involved. From the geometry, it is straightforward to 168 show that between ground and sky, and the two parallel walls

$$
x_{i}=x_{e}+H \tan \eta_{1} \cos \theta_{1} \text {, between sky and ground, }
$$

171 The incident coordinates of a ray transferring between two perpendicular surfaces are 172 slightly more complicated, as given by 


$$
x_{i}=\frac{z_{e}}{\tan \eta_{1} \cos \theta_{1}} \text {, from walls to sky/ground, }
$$

$$
z_{i}=\frac{x_{e}}{\tan \eta_{1} \cos \theta_{1}}, \text { from sky/ground to walls }
$$

175 Tracing a ray emitting from surface $A_{1}$ with random motion, it is relatively straightforward 176 to see if it actually absorbed by surface $A_{2}$ using Monte Carlo algorithm, by checking the 177 incident coordinates. For example, if the incidental horizontal coordinate falls within the 178 spatial location of ground, i.e. $0 \leq x_{i} \leq W$, the emitted ray is considered as received by the 179 ground; it is “missed” by the ground otherwise.

180

181 185 186

\subsection{Matrix solution of net radiation}

Given $i$-th facet in a street canyon, with $1 \leq i \leq N$ and $N$ the total number of facets, it is associated with a range of radiative fluxes, namely the irradiance (i.e. the total incoming radiation) $I_{i}$, the radiosity (the total outgoing) $J_{i}$, the emittance (the total emitted) $M_{i}$, and the net radiative flux $Q_{i}$, respectively. Assuming all facets are opaque, these fluxes are not independent but related by

$$
\begin{gathered}
I_{i}=\sum_{j=1}^{N} J_{j} F_{j i}, \\
J_{i}=M_{i}+\left(1-\varepsilon_{i}\right) I_{i}, \\
Q_{i}=M_{i}-J_{i},
\end{gathered}
$$

190 where subscripts ' $i$ ' and ' $j$ ' are facet indices, $\varepsilon$ is the emissivity and $F_{j i}$ are the view factors

191 for radiation transfer from $j$-th to $i$-th surface, as defined in Eq. (1).

The quantity of interest is the net radiation flux, which involves the radiosity from

193 other facets incident on the surface of interest. Combining Eqs. (15) and (16), we have 


$$
J_{i}=M_{i}+\left(1-\varepsilon_{i}\right) \sum_{j=1}^{N} J_{j} F_{j i} .
$$

195 Clearly the solution of the problem involves recurrence of radiosity at a generic surface $J_{i}$.

196 Exact solution therefore invokes solving the geometric series associated with multiple 197 (infinite) radiative reflections. Rewrite Eq. (18) as

$$
M_{i}=J_{i}-\left(1-\varepsilon_{i}\right) \sum_{j=1}^{N} J_{j} F_{j i}=\sum_{j=1}^{N} J_{j} \Gamma_{j i},
$$
where $\Gamma_{i j}=\delta_{i j}-\left(1-\varepsilon_{i}\right) F_{i j}$. The matrix $\Gamma_{i j}$ always has an inverse, which is denoted as $\left[\Psi_{i j}\right]=\left[\Gamma_{i j}\right]^{-1}$. Thus for each facet, we have

$$
J_{i}=\sum_{j=1}^{N} M_{j} \Psi_{j i}, I_{i}=\frac{J_{i}-M_{i}}{1-\varepsilon_{i}},
$$

202 and

$$
Q_{i}=\left\{\begin{array}{ll}
\sum_{j=1}^{N} F_{j i} M_{j}-M_{i} & \text { if } \varepsilon_{i}=1 \\
\frac{\varepsilon_{i} \sum_{j=1}^{N} \Psi_{j i} M_{j}-M_{i}}{1-\varepsilon_{i}} & \text { if } \varepsilon_{i} \neq 1
\end{array} .\right.
$$

204 For each facet, the material emissivity and temperature are known quantities. For diffusive 205 thermal radiation, the emittance is diffuse and longwave in nature, and can thus be 206 expressed using Boltzmann’s law: where $\sigma=5.67 \times 10^{-8} \mathrm{~W} \mathrm{~m}^{-2} \mathrm{~K}^{-4}$ is the Stephen-Boltzmann constant. Note that Eqs. (20)-

209 (21) represent the matrix solution of radiative heat exchange between canyon facets. When 210 the view factor matrix $F_{i j}$ is analytically determined, these solutions are hereafter referred 
211 to as "exact" for they analytically resolves infinite number of reflections between canyon 212 surfaces through matrix inversion.

213

\section{$214 \quad 3 . \quad$ Model Validation}

215 In this section, we first examine that if the radiative view factors predicted by Monte 216 Carlo algorithm agree with the analytical values for a bare street canyon absent of trees. 217 Next, the predicted view factors are used in the matrix method for prediction of net 218 radiation arising from canyon facets under thermal equilibrium. Lastly, the validated 219 Monte Carlo algorithm will be applied to estimate ground and wall temperatures in a real 220 street canyon during a night cooling episode.

\subsection{Estimation of radiative view factors}

The numerical algorithm for estimating view factors using Monte Carlo simulations

224 (MCS) is outlined in Eqs. (8)-(14). Using random samples, the accuracy of Monte Carlo 225 method, as expected, improves with the sample size. Taking the view factor between sky 226 and ground $F_{S G}$ as example, Figure 3 shows the model accuracy as a function of number of 227 samples. With a sample size of 1,000 , MCS is capable of predicting the view factor with 228 reasonable accuracy, as compared to the analytical formulation, while MCS with a sample 229 size of 10,000 yields results with negligible discrepancy. For subsequent simulations, we 230 will use the sample size of 10,000. Predictions of other street canyon view factors exhibit 231 similar trend with respect to sample size. The comparisons of all four view factors between 232 urban facets by Monte Carlo and analytical methods are shown in Figure 4. The 
233 discrepancy between predictions by the two methods is nearly indiscernible, for canyon

234 aspect ratio $H / W$ ranging from 0.01 to 100 . Also note that the most drastic change of all

235 four view factors occur around $H / W \sim 1.0$, and covers the practical range of actual street

236 canyon dimensions around 0.2 to 10. This observation highlights the importance of 237 accurate prediction of radiative view factors for real street canyons.

238

\subsection{Net radiation of canyon facets in thermal equilibrium}

With the view factors being accurately estimated by the Monte Carlo method, we

241 then apply the method to predict the net radiation from each urban facet under thermal 242 equilibrium, in conjunction with the matrix method outlined in Section 2.2. Emissivity is

243 set to be 1.0 for sky (canyon top) $\varepsilon_{W}=\varepsilon_{G}=0.95$, where subscripts $W$ and $G$ denote 244 properties of walls and the ground, respectively. The surfaces enclosing the street canyon 245 (c.f. Figure 2) are set to be in constant temperatures as: sky $T_{a}=300 \mathrm{~K}$, ground $T_{G}=290 \mathrm{~K}$, 246 east wall $T_{W 1}=290 \mathrm{~K}$, and west well $T_{W 2}=295 \mathrm{~K}$. Note that these values are chosen rather 247 arbitrarily for demonstration purpose, and they do not affect the accuracy of the model 248 predictions. The results of comparison between the Monte Carlo and the exact methods, as

249 functions of the canyon aspect ratio, are shown in Figure 5: here the exact solution refers to 250 the combination of analytical formulation of view factors in Eqs. (4)-(7) and the matrix 251 method for net radiation with infinite reflections in Section 2.2. It is clear that the MCS 252 predictions are in good agreement with the exact solution. As a function of canyon aspect 253 ratio, the most significant variation happens again around $H / W \sim 1.0$, indicating the view 254 factors are dominating the radiative energy distribution among different street canyon 255 facets. It is also noteworthy that the model is capable of resolving differences in surface 
256 temperatures of two opposite walls, given that their net radiation can be accurately 257 determined.

258

$259 \quad$ 3.3. Transient nocturnal cooling episode

260 Given that the proposed model is capable of predicting both view factor and net 261 radiation with good accuracy as compared to the analytical method, here we further test the 262 model for its capability of predicting surface temperatures, in conjunction with numerical 263 procedures for heat conduction. In this study, we adopt a spatially-analytical scheme for 264 solving heat conduction through solid ground and walls, based on the Green's function 265 approach (Wang et al., 2011a). The temperature distribution for a finite wall with one266 dimensional (1D) spatial domain $0 \leq x \leq d$ where $d$ is the wall thickness, is given by a 267 convolution integral equation as (Carslaw and Jaeger 1959; Cole et al., 2011):

268

$$
T_{W}(x, t)=T_{i, W}+\int_{0}^{t} q_{1}(t-\tau) d G(x, \tau)-\int_{0}^{t} q_{2}(t-\tau) d G(d-x, \tau),
$$

269 where $q_{1}$ and $q_{2}$ are the heat fluxes at the two surfaces of the wall; and $G$ is the Green's 270 function (fundamental) solution of a homogeneous heat conduction problem. For a finite 271 wall with thickness $d$, the Green's function solution is given by

$$
\begin{aligned}
G(x, t) & =\frac{2 \sqrt{(\alpha t / \pi)}}{k} \sum_{n=-\infty}^{\infty} \exp \left[-\frac{(x-2 n d)^{2}}{4 \alpha t}\right], \\
& -\frac{1}{k} \sum_{n=-\infty}^{\infty}|x-2 n d| \operatorname{erfc}\left(\frac{|x-2 n d|}{2 \sqrt{\alpha t}}\right)
\end{aligned}
$$

273 where $k$ and $\alpha$ are the thermal conductivity and diffusivity, respectively; and erfc(.) is the 274 complimentary error function. Equations (23)-(24) can be readily evaluated using 
275 numerical integration, given the knowledge of boundary conditions $q_{1}$ and $q_{2}$, and the

276 initial condition $T_{i}$. A detailed solution procedure for Green's function approach can be 277 found in Wang et al. (2011a).

Note that canyon ground, unlike walls bounded by two (building interior and exterior) 279 boundaries, can be treated as a 1D semi-infinite solid domain, bounded only at the upper 280 surface with an effective adiabatic (zero flux) condition at the lower boundary (in deep 281 soil). Thus the solution of surface temperature of the ground can be approximated by a 282 closed-form formula (Nunez et al., 1976; Wang et al., 2011a), as

$$
T_{s, G}(t)=T_{i, G}+Q_{G} \frac{2 \sqrt{\alpha_{G} t / \pi}}{k_{G}},
$$

284 where $T_{s}$ is the surface temperature; and $Q_{G}$ is the net radiation received at the ground 285 surface, as predicted using matrix method with infinite reflections by Eq. (21). The proposed method is tested for a nocturnal cooling event in the Grand-view 287 district of Vancouver, measured by Nunez and Oke (1976) during September 9-11, 1973. 288 The street canyon dimensions are $d=0.3 \mathrm{~m}, H=7.31 \mathrm{~m}$, and $W=7.54 \mathrm{~m}$. Thermal 289 properties of walls and the ground are: $\left(\rho c_{p}\right)_{W}=2.09 \times 10^{6} \mathrm{~J} \mathrm{~K}^{-1} \mathrm{~m}^{-3}, k_{W}=1.6 \mathrm{~W} \mathrm{~m}^{-1} \mathrm{~K}^{-1}$, $290\left(\rho c_{p}\right)_{G}=1.88 \times 10^{6} \mathrm{~J} \mathrm{~K}^{-1} \mathrm{~m}^{-3}, k_{G}=1.6 \mathrm{~W} \mathrm{~m}^{-1} \mathrm{~K}^{-1}$, where $\rho$ an $c_{p}$ are the density and 291 specific heat; and $\varepsilon_{W}=\varepsilon_{G}=0.95$. The nocturnal cooling episode was measured after sunset 292 with calm winds, so the short wave radiation, sensible and latent heat fluxes are neglected 293 in both the measurement and modelling. The initial longwave radiation is measured as 339 $294 \mathrm{~W} \mathrm{~m} \mathrm{~m}^{-2}$. Surface temperatures of the canyon walls and ground predicted by the combined 295 numerical framework (Monte Carlo simulation of view factors, matrix method for net 296 radiation, and Green’s function approach for heat conduction), are compared with field 
measurements, as shown in Figure 6. The overall agreement between model predictions

298 and observations is reasonably good, with temperature discrepancy less than $1{ }^{\circ} \mathrm{C}$ in 299 general.

300

\section{$301 \quad$ 4. Model applications and discussion}

302

304

305

With the proposed numerical framework validated against benchmark radiative transfer problems and in-situ measurements, we proceed to apply the model to street canyons with shade trees. We first test the effect of tree crown sizes on view factors between canyon facets, followed by its implications to surface temperature evolution and building energy consumption given diurnal atmospheric forcing. Some of the assumptions made in the proposed methods and future model extensions are also discussed.

\subsection{Effect of tree sizes on view factors}

For simplicity, we ignore the size of tree trunks due to its relative small dimension as compared to tree crowns. Further, in this study, tree crowns assume circular cross-sectional shapes, as shown in Figure 2, with a radius of $R_{t}$. As the vertical variability is not explicitly resolved in the 2D urban canyon, and subsequently in the single layer UCM adopted in WRF, we do not account complex tree geometries, e.g. roof top shading and probabilistic distribution of tree heights in this paper, such as those developed in multi-layer UCMs by Krayenhoff et al (2014). With presence of trees in the street canyon, radiative exchange between canyon facets will be partially "blocked" by tree crowns. Thus, trees will effectively shade canyon facets by intercepting radiative rays, with their actual shading 
319 effect depending on the size of the tree crowns. Figure 7 demonstrates this shading effect

as a function of canyon aspect ratio. Note that even with a very small tree crown size $\left(R_{t} / W\right.$

$321=0.1$ ), all radiative view factors are effectively reduced. As tree crown size increases,

322 more radiation will be intercepted by trees and view factors further decrease. In addition,

323 the shading effect is more significant for shallower canyons (with smaller $H / W$ ratios).

324 This is because for deep canyons, walls in the street canyon are already presented an

325 important factor for shading, and the additional shading by trees are less prominent.

\subsection{Canyon temperature and building energy consumption}

Next, we apply the combined numerical framework to test the effect of tree sizes on

diurnal evolution of canyon temperatures and building energy use. The model is driven by in-situ measurement of atmospheric and radiative forcings at Maryvale, Phoenix, Arizona on 04 June 2012 (clear day), measured by an eddy covariance flux tower. More details on the instrumentation and data quality control of the field measurement can be found in

333 Chow et al. (2014). Relevant models parameters are given by measurement or previous 334 model calibration as: $d=0.3 \mathrm{~m}, H=15 \mathrm{~m}, W=20 \mathrm{~m}, k_{G}=1.6 \mathrm{~W} \mathrm{~m}^{-1} \mathrm{~K}^{-1}$, $k_{W}=1.3 \mathrm{~W} \mathrm{~m}^{-1} \mathrm{~K}^{-1},\left(\rho c_{p}\right)_{W}=1.26 \times 10^{6} \mathrm{~J} \mathrm{~K}^{-1} \mathrm{~m}^{-3}, \quad\left(\rho c_{p}\right)_{G}=2.00 \times 10^{6} \mathrm{~J} \mathrm{~K}^{-1} \mathrm{~m}^{-3}$, and $\varepsilon_{W}=$ $336 \varepsilon_{G}=0.95$. Diurnal variation of the atmospheric temperature and net (shortwave + 337 longwave) downwelling radiation at the canyon top is plotted in Figure 8(a).

Note that this paper is focused on the radiative exchange in a street canyon, so turbulent (sensible and latent) heat fluxes are not accounted in energy transport. For an arid 
341 irradiance), while the sensible heat flux can be significant (maximum daily sensible heat is

$342300 \mathrm{~W} \mathrm{~m}^{-2}$ on June 04, 2012 in Phoenix). So the negligence of turbulent heat is a crude

343 assumption. To include sensible and latent heat in surface energy balance, it requires

344 sophisticated physical parameterization schemes involving wind velocity, surface

345 roughness, atmospheric stability, humidity, soil moisture, and complex hydrological

346 processes (precipitation, infiltration, and surface runoff) (see Wang et al., 2013). It remains

347 a challenging task to build a complete land surface model based on stochastic simulations

348 including all physical processes. Furthermore, the Monte Carlo algorithm assumes

349 completely random emission angles of a ray (see Eqs. (8)-(9)), i.e. canyon facets are

350 Lambertian and opaque, and radiative rays are diffusive. This is not the case when direct

351 solar radiation is first impinged on a canyon facet. A sun-lit wall when receiving

352 directional solar radiation, for example, is certainly at higher temperature than a shaded

353 wall. One way to include that effect is to estimate a "shadow length" in a street canyon as a

354 function of city location, canyon orientation, and time of the day (Kusaka et al., 2001).

355 Nevertheless, the assumption of diffusive radiation is valid for subsequent reflections using

356 the matrix method.

357 A comparison of model estimate of ground surface temperature and field 358 measurements is shown in Figure 8(b), with no tree shading in the model. Despite the 359 above-mentioned limitation of the model, its prediction is comparable with the 360 measurement (with a $R^{2}=0.945$ ). Next, we include shade trees in the canyon with different 361 crown sizes. The result of model predictions for diurnal evolution of canyon surface 362 temperatures is shown in Figure 9(a). The shading effect is clearly demonstrated in that 363 when the tree crown size increases, surface temperatures of wall and ground decrease. A 
364 increase of crown size from $0.5 \mathrm{~m}$ to $1.0 \mathrm{~m}$ leads to the reduction of surface temperatures 365 up to $6-7^{\circ} \mathrm{C}$ around noon.

366 Given the temperature profile through the wall is calculated using the Green's 367 function approach in Eq. (23), the conductive heat flux entering the building can be 368 computed using Fourier’s law,

$$
q_{W}(x, t)=-k \frac{d T_{W}}{d x}=-k\left[\int_{0}^{t} q_{1}(t-\tau) d G^{\prime}(x, \tau)-\int_{0}^{t} q_{2}(t-\tau) d G^{\prime}(d-x, \tau)\right]
$$

at $x=d$. This flux is a good indicator for energy consumption inside the building to offset

371 the heat inflow/outflow through building envelop and to maintain the interior thermal

372 comfort through operation of heating, ventilation, and air-conditioning systems. The model

373 predicted heat flux entering the building through wall is presented in Figure 9(b), for

374 various tree sizes. Again, it is clear that in the absence of trees, building interiors receives

375 large heat inflow (positive) through the wall in a clear summer day (June 04). When trees

376 are presented, the magnitude of heat inflow decreases significantly with the tree size,

377 indicating the potential of shade trees for building energy saving.

\section{5. Concluding remarks}

380 A new numerical framework is developed for radiative heat exchange in street canyons

381 with shade trees, by combining the Monte Carlo simulation of view factors and matrix

382 method for infinite reflections. The model is validated against analytical solutions of

383 benchmark radiative transfer problems as well as field measurements in real street canyons.

384 Results of comparison show that the model is of capable of predicting radiative view 
385 factors, surface temperatures, and net radiation of canyon facets with good accuracy, in 386 both steady state and transient cases. We then apply the model to study the effect of shade 387 trees and their sizes on the diurnal evolution of canyon surface temperatures in conjunction 388 with a Green’s function approach for heat conduction. It is manifested that shade trees are 389 effective in reducing canyon surface temperatures, with the shading effect enhanced by 390 increasing tree sizes. The presence of trees in a street canyon demonstrates good potential 391 in reducing cooling energy consumption as it mitigates the heat inflow into the building 392 through walls.

393 In addition, Monte Carlo method is also a powerful tool in computing absorption and 394 scattering of radiation if complex participating media (e.g. dust, soot, pollen, etc.) are 395 presented in street canyons. By randomizing radiation using energy bundles, scattering 396 deflects a ray's direction, and absorption causes a ray to be intercepted. The frequency, 397 direction, and fraction of attenuation due to either scattering or absorption can be simulated 398 by random numbers and as functions of scattering or absorption coefficients. This 399 treatment is particularly useful for cities with heavy atmospheric pollution, either caused 400 by natural sources with seasonal occurrence or by constant industrial sources. By inclusion 401 of participating media, numerical models will improve accuracy in simulating radiative 402 exchange and thermal field in an urban canopy layer, which will subsequently enhance 403 numerical capacity in, e.g. building energy model or land-atmosphere interactions. 


\section{Acknowledgements}

405 This work is supported by the National Science Foundation (NSF) under grant 406 number CBET-1435881. Partial financial support by the Central Arizona-Phoenix Long407 Term Ecological Research (CAP LTER) project under NSF grant CAP3: BCS-1026865 is 408 gratefully acknowledged.

409 


\section{References:}

411 Akbari, H., Pomerantz, M., Taha, H., 2001. Cool surfaces and shade trees to reduce energy use and improve air quality in urban areas. Sol. Energy 70, 295-310.

Aoyagi, T., Takahashi, S., 2012. Development of an urban multilayer radiation scheme and its application to the urban surface warming potential. Boundary-Layer Meteorol. 142, 305-328.

Arnfield, A.J., 2003. Two decades of urban climate research: A review of turbulence, exchanges of energy and water, and the urban heat island. Int. J. Climatol. 23, 1-26.

Carslaw, H.S., Jaeger, J.C., 1959. Conduction of Heat in Solids. Oxford University Press Oxford, 510pp.

Chen, F., Kusaka, H., Bornstein, R., Ching, J., Grimmond, C.S.B., Grossman-Clarke, S., Loridan, T., Manning, K.W., Martilli, A., Miao, S.G., Sailor, D., Salamanca, F.P., Taha, H., Tewari, M., Wang, X.M., Wyszogrodzki, A.A., Zhang, C.L., 2011. The integrated WRF/urban modelling system: development, evaluation, and applications to urban environmental problems. Int. J. Climatol. 31, 273-288.

Chow, W.T., Volo, T.J., Vivoni, E.R., Jenerette, G.D., Ruddell, B.L., 2014. Seasonal dynamics of a suburban energy balance in Phoenix, Arizona. Int. J. Climatol. Published online, DOI:10.1002/joc.3947.

Cole, K.D., Haji-Sheikh, A., Beck, J.V., Litkouhi, B., 2011. Heat Conduction using Green's Functions. Taylor \& Francis Boca Raton, 653pp.

Grimmond, C.S.B., Blackett, M., Best, M.J., Baik, J.J., Belcher, S.E., Beringer, J., Bohnenstengel, S.I., Calmet, I., Chen, F., Coutts, A., Dandou, A., Fortuniak, K., Gouvea, M.L., Hamdi, R., Hendry, M., Kanda, M., Kawai, T., Kawamoto, Y., Kondo, 
H., Krayenhoff, E.S., Lee, S.H., Loridan, T., Martilli, A., Masson, V., Miao, S., Oleson, K., Ooka, R., Pigeon, G., Porson, A., Ryu, Y.H., Salamanca, F., Steeneveld, G.J., Tombrou, M., Voogt, J.A., Young, D.T., Zhang, N., 2011. Initial results from Phase 2 of the international urban energy balance model comparison. Int. J. Climatol. 31, 244-272.

Grimmond, C.S.B., Blackett, M., Best, M.J., Barlow, J., Baik, J.J., Belcher, S.E., Bohnenstengel, S.I., Calmet, I., Chen, F., Dandou, A., Fortuniak, K., Gouvea, M.L., Hamdi, R., Hendry, M., Kawai, T., Kawamoto, Y., Kondo, H., Krayenhoff, E.S., Lee, S.H., Loridan, T., Martilli, A., Masson, V., Miao, S., Oleson, K., Pigeon, G., Porson, A., Ryu, Y.H., Salamanca, F., Shashua-Bar, L., Steeneveld, G.J., Tombrou, M., Voogt, J., Young, D., Zhang, N., 2010. The international urban energy balance models comparison project: First results from Phase 1. J. Appl. Meteorol. Climatol. 49, 12681292.

Grimmond, C.S.B., Oke, T.R., 1999. Aerodynamic properties of urban areas derived from analysis of surface form. J. Appl. Meteorol. 38, 1262-1292.

Harman, I.N., Best, M.J., Belcher, S.E., 2004. Radiative exchange in an urban street canyon. Boundary-Layer Meteorol. 110, 301-316.

Howell, J.R., 1968. Application of Monte Carlo to heat transfer problems, in: Irvine Jr., T.F., Hartnett, J.P. (Eds.) Advances in Heat Transfer, Vol 5, Academic Press, New York, pp. 54.

Howell, J.R., 1998. The Monte Carlo method in radiative heat transfer. J. Heat Transf. 120, 547-560. 
Kikegawa, Y., Genchi, Y., Yoshikado, H., Kondo, H., 2003. Development of a numerical simulation system toward comprehensive assessments of urban warming countermeasures including their impacts upon the urban buildings' energy-demands. Appl. Energy 76, 449-466.

Krayenhoff, E.S., Christen, A., Martilli, A., Oke, T.R., 2014. A multi-layer radiation model for urban neighbourhoods with trees. Boundary-Layer Meteorol. 151, 139-178.

Kusaka, H., Kondo, H., Kikegawa, Y., Kimura, F., 2001. A simple single-layer urban canopy model for atmospheric models: Comparison with multi-layer and slab models. Boundary-Layer Meteorol. 101, 329-358.

Lemonsu, A., Masson, V., Shashua-Bar, L., Erell, E., Pearlmutter, D., 2012. Inclusion of vegetation in the Town Energy Balance model for modelling urban green areas. Geosci. Model Dev. 5, 1377-1393.

Li, Z.Q., Xia, X.G., Cribb, M., Mi, W., Holben, B., Wang, P.C., Chen, H.B., Tsay, S.C., Eck, T.F., Zhao, F.S., Dutton, E.G., Dickerson, R.R., 2007. Aerosol optical properties and their radiative effects in northern China. J. Geophys. Res.-Atmos. 112, D22S01.

Nunez, M., Oke, T.R., 1976. Long-wave radiative flux divergence and nocturnal cooling of the urban atmosphere. Boundary-Layer Meteorol. 10, 121-135.

Ouldboukhitine, S.E., Belarbi, R., Sailor, D.J., 2014. Experimental and numerical investigation of urban street canyons to evaluate the impact of green roof inside and outside buildings. Appl. Energy 114, 273-282.

Prabhakar, G., Betterton, E.A., Conant, W., Herman, B.M., 2014. Effect of urban growth on aerosol optical depth - Tucson, Arizona, 35 years later. J. Appl. Meteorol. Climatol. 53, 1876-1885. 
478

479

480

481

482

483

484

485

486

487

488

489

490

491

492

493

494

495

496

497

498

499

Robinson, D., Stone, A., 2004. Solar radiation modelling in the urban context. Sol. Energy 77, 295-309.

Robinson, D., Stone, A., 2005. A simplified radiosity algorithm for general urban radiation exchange. Building Serv. Eng. Res. Technol. 26, 271-284.

Robinson, D., Stone, A., 2006. Internal illumination prediction based on a simplified radiosity algorithm. Sol. Energy 80, 260-267.

Sailor, D.J., Resh, K., Segura, D., 2006. Field measurement of albedo for limited extent test surfaces. Sol. Energy 80, 589-599.

Santamouris, M., 2014. Cooling the cities - A review of reflective and green roof mitigation technologies to fight heat island and improve comfort in urban environments. Sol. Energy 103, 682-703.

Santamouris, M., Papanikolaou, N., Livada, I., Koronakis, I., Georgakis, C., Argiriou, A., Assimakopoulos, D.N., 2001. On the impact of urban climate on the energy consumption of buildings. Sol. Energy 70, 201-216.

Sparrow, E.M., Cess, R.D., 1978. Radiation Heat Transfer, Augmented Ed., HarperCollins, London, UK.

Sun, Y.L., Zhuang, G.S., Tang, A.H., Wang, Y., An, Z.S., 2006. Chemical characteristics of PM2.5 and PM10 in haze-fog episodes in Beijing. Environ. Sci. Technol. 40, 31483155.

Synnefa, A., Santamouris, M., Apostolakis, K., 2007. On the development, optical properties and thermal performance of cool colored coatings for the urban environment. Sol. Energy 81, 488-497. 
500 Taha, H., 1997. Urban climates and heat islands: Albedo, evapotranspiration, and 501 anthropogenic heat. Energy Build. 25, 99-103.

502 United Nations, 2012. World urbanization prospects: The 2011 revision, The United 503 Nations' Department of Economic and Social Affairs - Population Division, New $504 \quad$ York, pp. 33.

505 Wang, Z.H., 2010. Geometric effect of radiative heat exchange in concave structure with 506 application to heating of steel I-sections in fire. Int. J. Heat Mass Transf. 53, 997$507 \quad 1003$.

508 Wang, Z.H., Bou-Zeid, E., Smith, J.A., 2011a. A spatially-analytical scheme for surface 509 temperatures and conductive heat fluxes in urban canopy models. Boundary-Layer $510 \quad$ Meteorol. 138, 171-193.

511 Wang, Z.H., Bou-Zeid, E., Au, S.K., Smith, J.A., 2011b. Analyzing the sensitivity of 512 WRF's single-layer urban canopy model to parameter uncertainty using advanced 513 Monte Carlo simulation. J. Appl. Meteorol. Climatol. 50, 1795-1814.

514 Wang, Z.H., Bou-Zeid, E., Smith, J.A., 2013. A coupled energy transport and hydrological 515 model for urban canopies evaluated using a wireless sensor network. Q. J. R. $516 \quad$ Meteorol. Soc. 139, 1643-1657.

517 Wong, N.H., Jusuf, S.K., Syafii, N.I., Chen, Y.X., Hajadi, N., Sathyanarayanan, H., 518 Manickavasagam, Y.V., 2011. Evaluation of the impact of the surrounding urban 519 morphology on building energy consumption. Sol. Energy 85, 57-71.

520 Yang, W.-J., Taniguchi, H., Kudo, K., 1995. Radiative heat transfer by the Monte Carlo 521 method, in: Hartnett, J.P., Irvine, T.F. (Eds.) Advances in Heat Transfer, Vol 27, $522 \quad$ Academic Press, San Diego, pp. 1-215. 


\section{Caption of Figures:}

525 Figure 1. Schematic of radiative transfer between two generic surfaces

526 Figure 2. Cross sectional view of 2D street canyon with trees. The cross section of tree 527 crowns is simplified as circles with radius $R_{t}$.

528 Figure 3. Effect of sample size on Monte Carlo prediction of view factor $F_{S G}$ : (a) as a 529 function of canyon aspect ratio, and (b) as a function of sample sizes at $H / W=1.0$.

530 Figure 4. View factors of radiative heat exchange between canyon facets as functions of 531 the canyon aspect ratio $H / W$; subscripts $S, G$, and $W$ denote sky, ground, and wall, 532 respectively. The sample size is 10,000 for the Monte Carlo simulations.

533 Figure 5. Comparison of net radiation of different canyon facets at thermal equilibrium, as 534 predicted by the exact and the proposed hybrid methods. Surface of the four enclosing 535 surfaces are set as $T_{a}=300 \mathrm{~K}, T_{G}=290 \mathrm{~K}, T_{W 1}=290 \mathrm{~K}$ and $T_{W 2}=295 \mathrm{~K}$.

536 Figure 6. Comparison of averaged wall and ground temperatures predicted by the model 537 and field measurements in the canyon during the night cooling episode.

538 Figure 7. Monte Carlo simulation of view factors of radiative heat exchange between 539 canyon facets with trees, as functions of the canyon aspect ratio $H / W$. In this case, the 540 canyon width $W$ is fixed as $20 \mathrm{~m}$, and the centre of tree crown height is located at $H / 2$.

541 Figure 8. Model application with (a) radiative forcing measured on 04 June 2012, Phoenix, 542 AZ, and (b) comparison between model prediction and measurement of ground surface 543 temperature.

544 Figure 9. Model prediction of diurnal variation of (a) surface temperatures, and (b) heat 545 conducted into building through walls. Diurnal radiative forcing is the same as in Figure 8. 


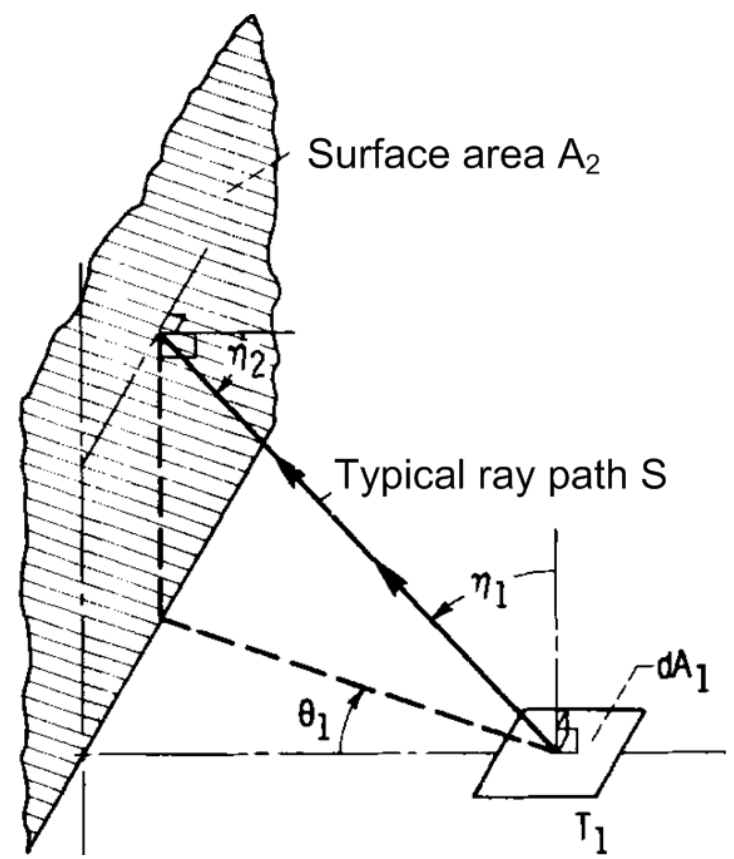

549 Figure 1. Schematic of radiative transfer between two generic surfaces 


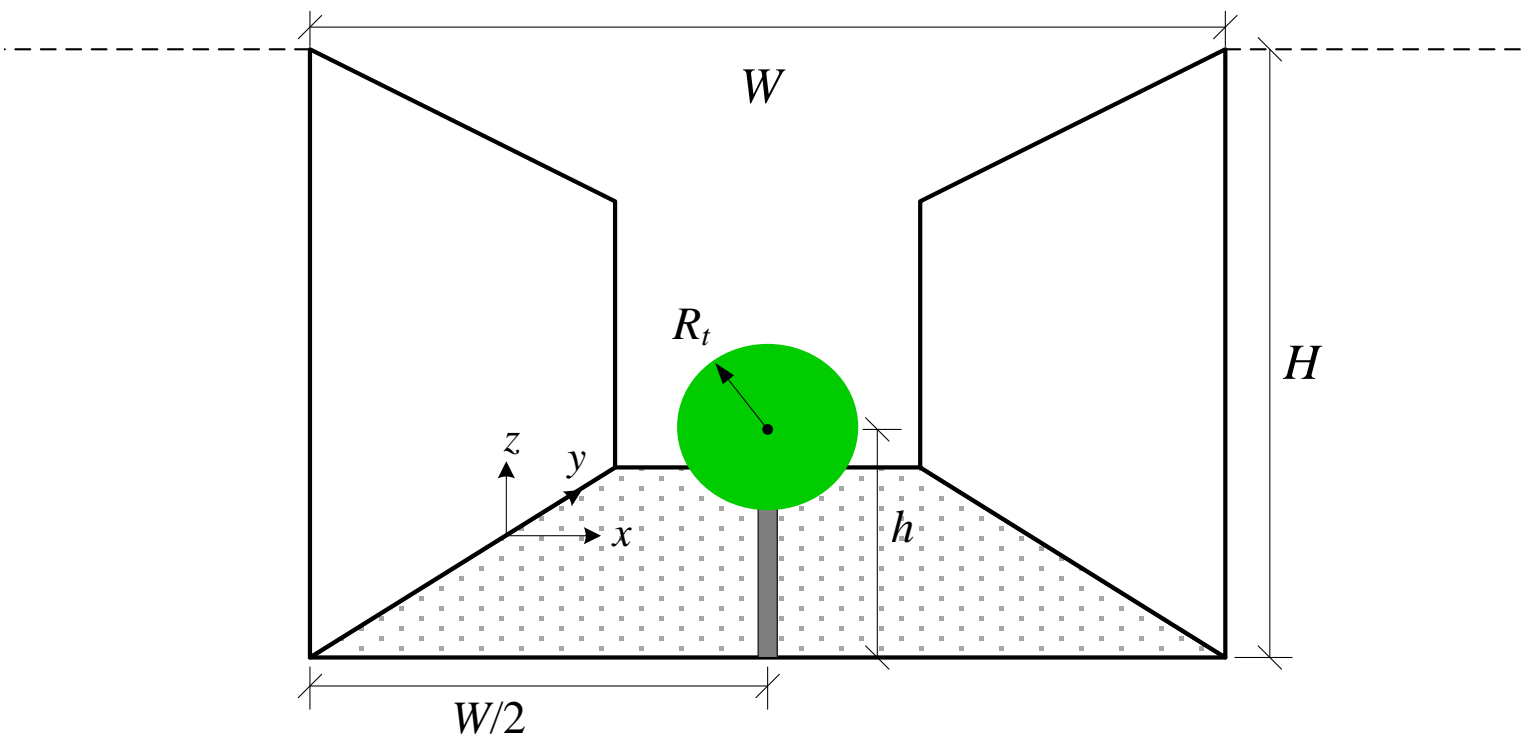

552 Figure 2. Cross sectional view of 2D street canyon with trees. The cross section of tree 553 crowns is simplified as circles with radius $R_{t}$. 
(a)

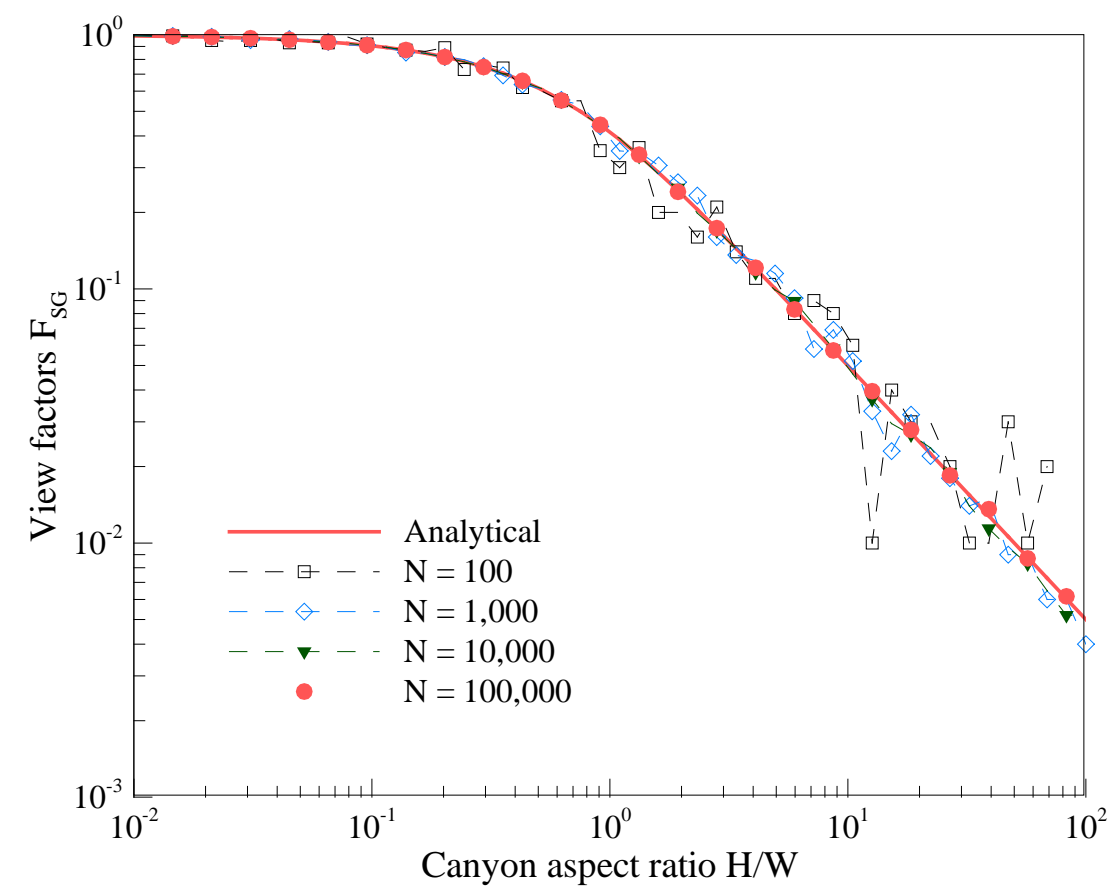

(b)

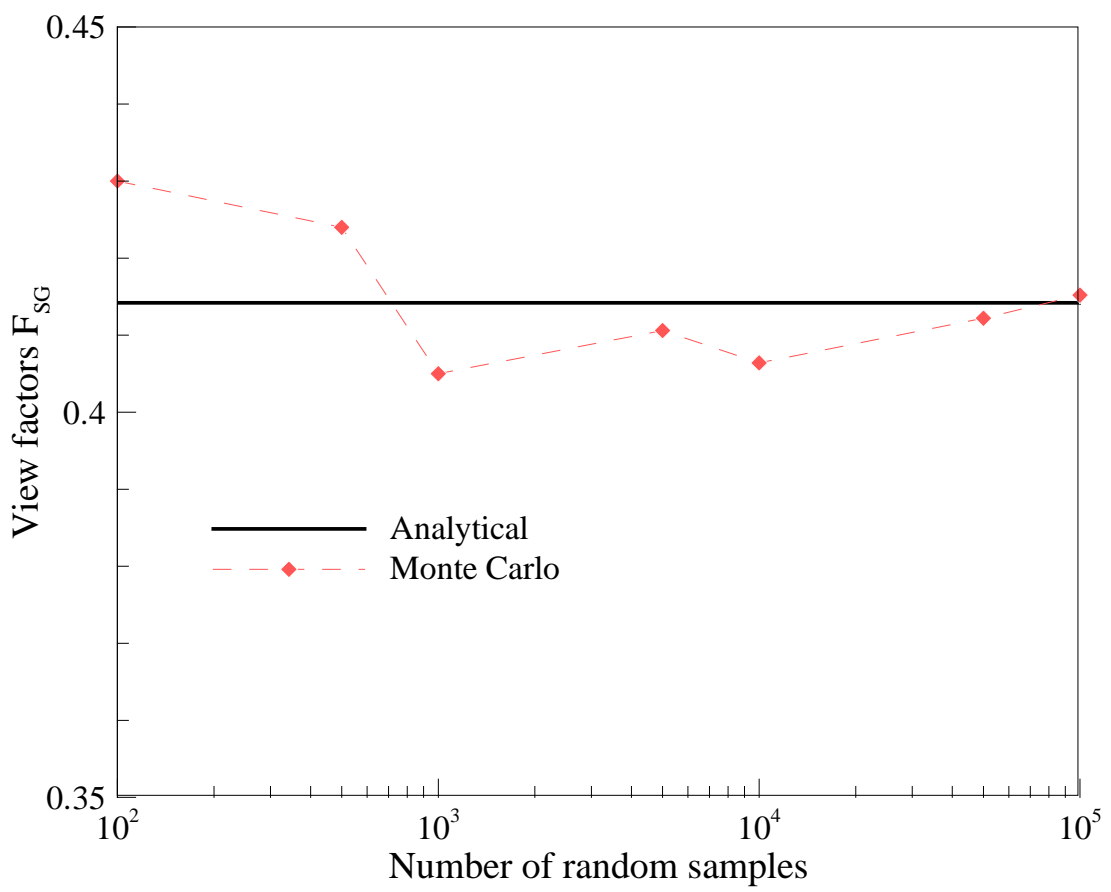

554

555 Figure 3. Effect of sample size on Monte Carlo prediction of view factor $F_{S G}$ : (a) as a 556 function of canyon aspect ratio, and (b) as a function of sample sizes at $H / W=1.0$. 


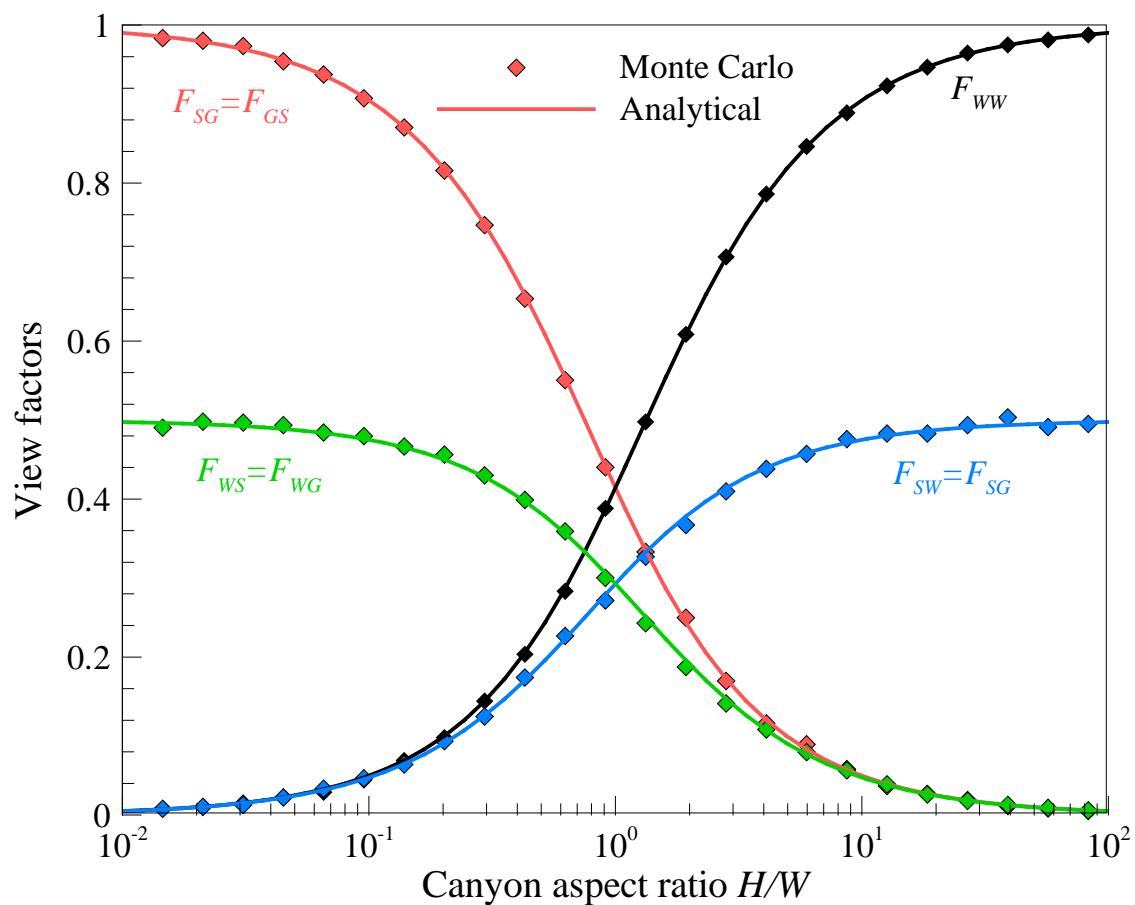

557

558 Figure 4. View factors of radiative heat exchange between canyon facets as functions of

559 the canyon aspect ratio $H / W$; subscripts $S, G$, and $W$ denote sky, ground, and wall,

560 respectively. The sample size is 10,000 for the Monte Carlo simulations. 


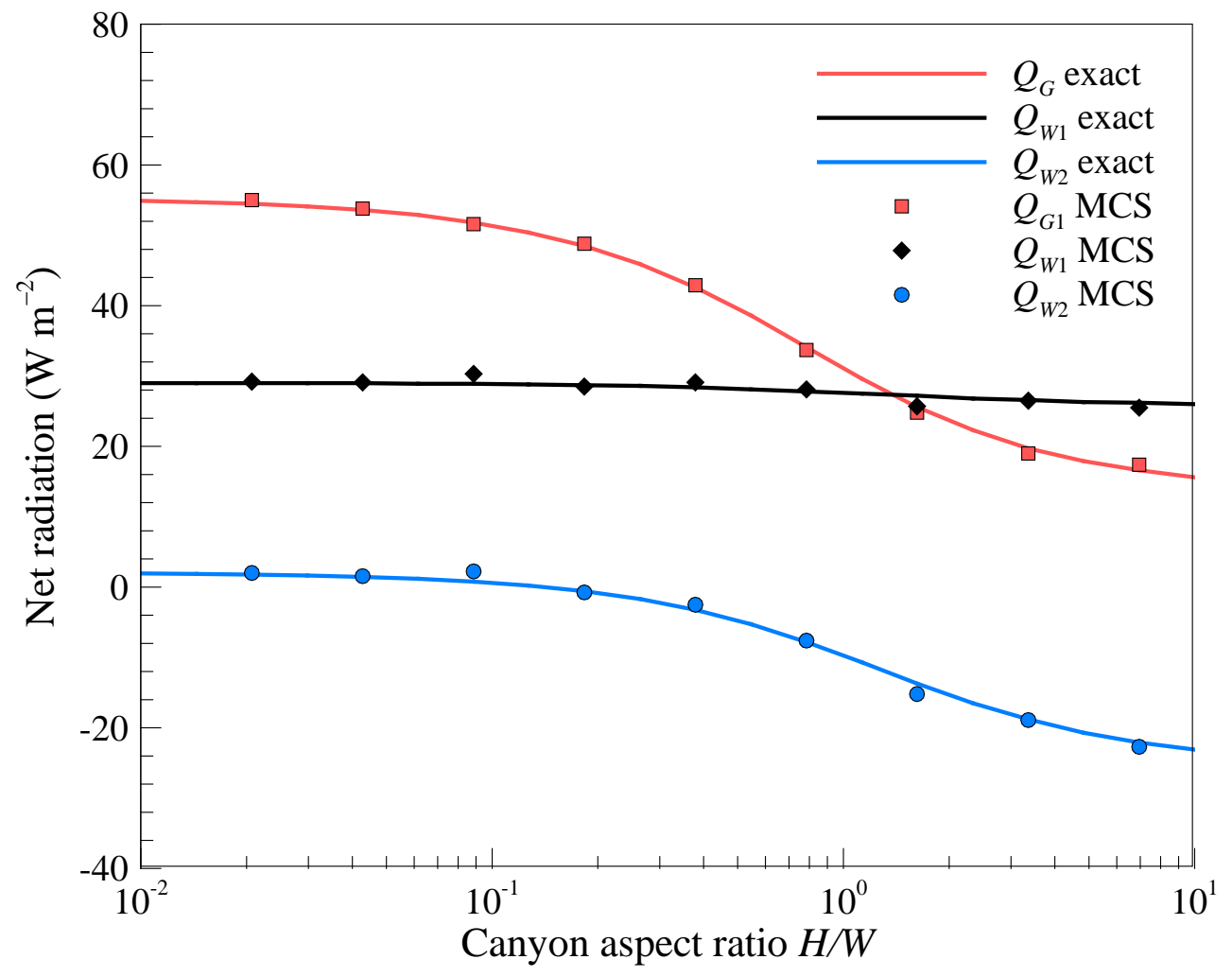

561

562 Figure 5. Comparison of net radiation of different canyon facets at thermal equilibrium, as

563 predicted by the exact and the proposed hybrid methods. Surface of the four enclosing

564 surfaces are set as $T_{a}=300 \mathrm{~K}, T_{G}=290 \mathrm{~K}, T_{W 1}=290 \mathrm{~K}$ and $T_{W 2}=295 \mathrm{~K}$. 


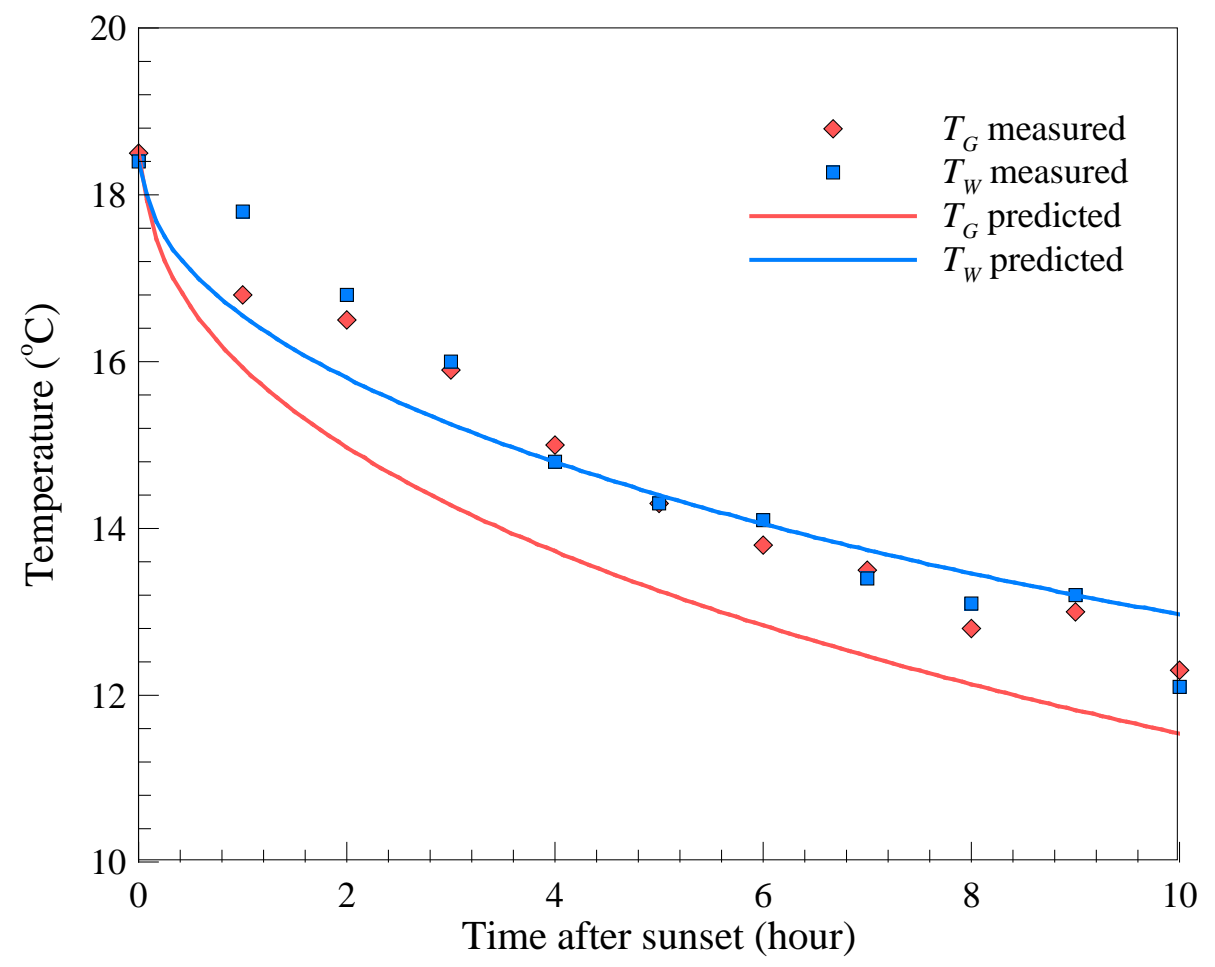

565

566 Figure 6. Comparison of averaged wall and ground temperatures predicted by the model 567 and field measurements in the canyon during the night cooling episode. 


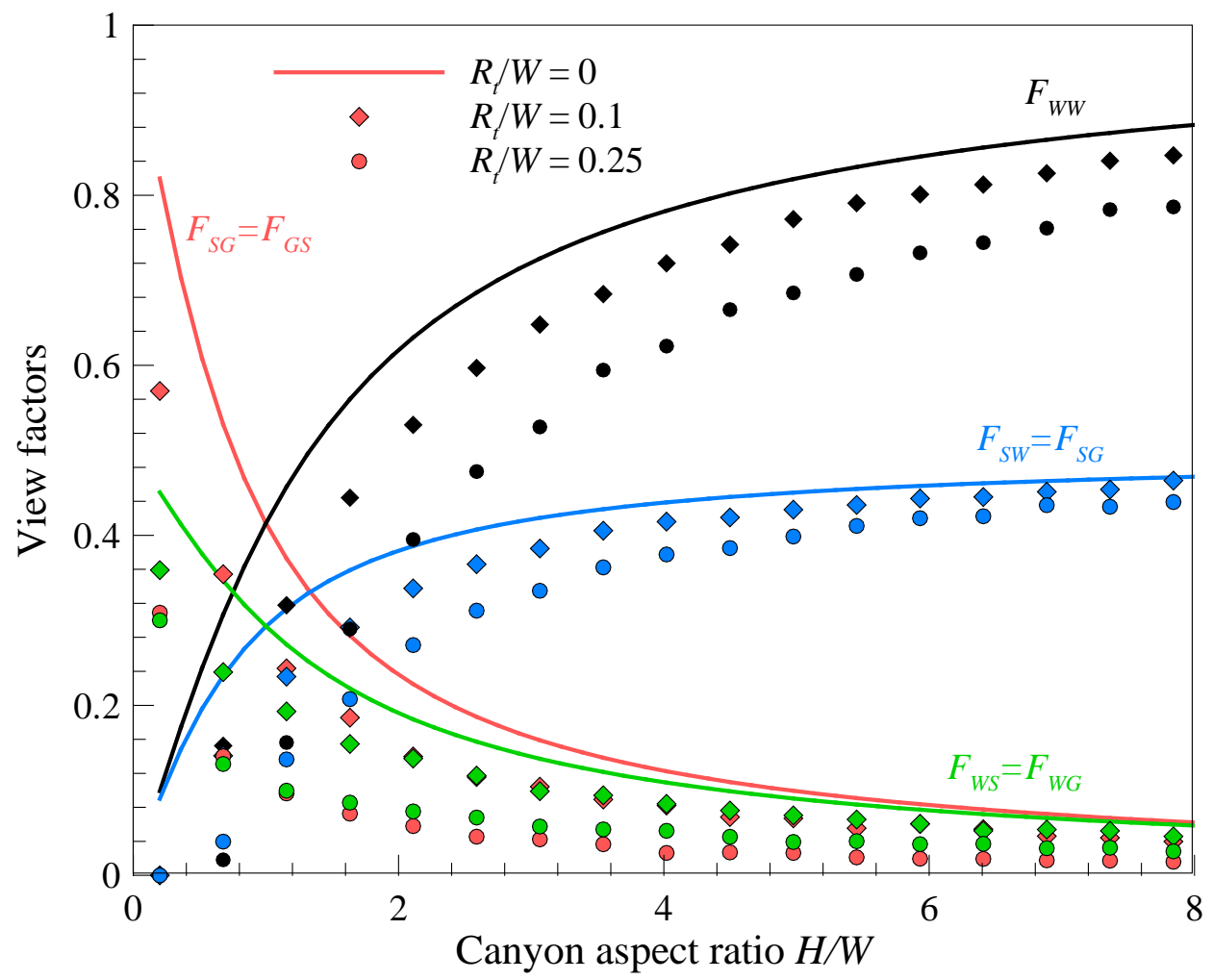

568

569 Figure 7. Monte Carlo simulation of view factors of radiative heat exchange between

570 canyon facets with trees, as functions of the canyon aspect ratio $H / W$. In this case, the

571 canyon width $W$ is fixed as $20 \mathrm{~m}$, and the centre of tree crown height is located at $H / 2$. 
(a)

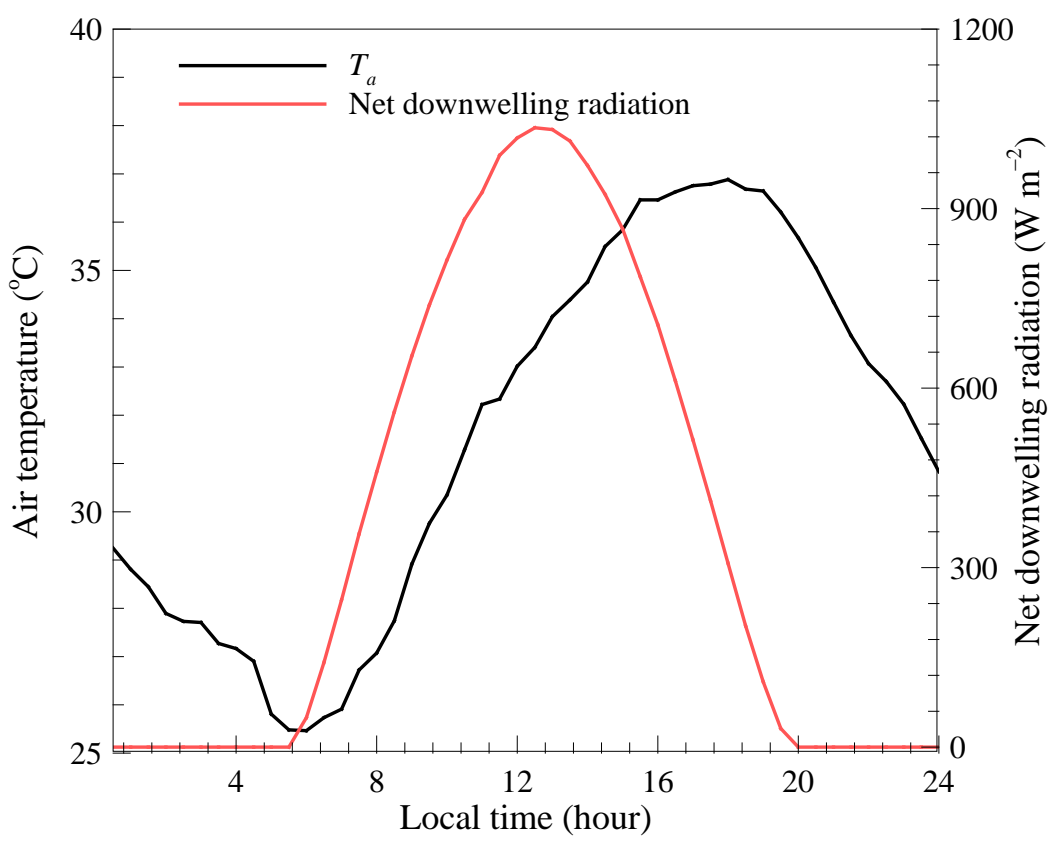

(b)

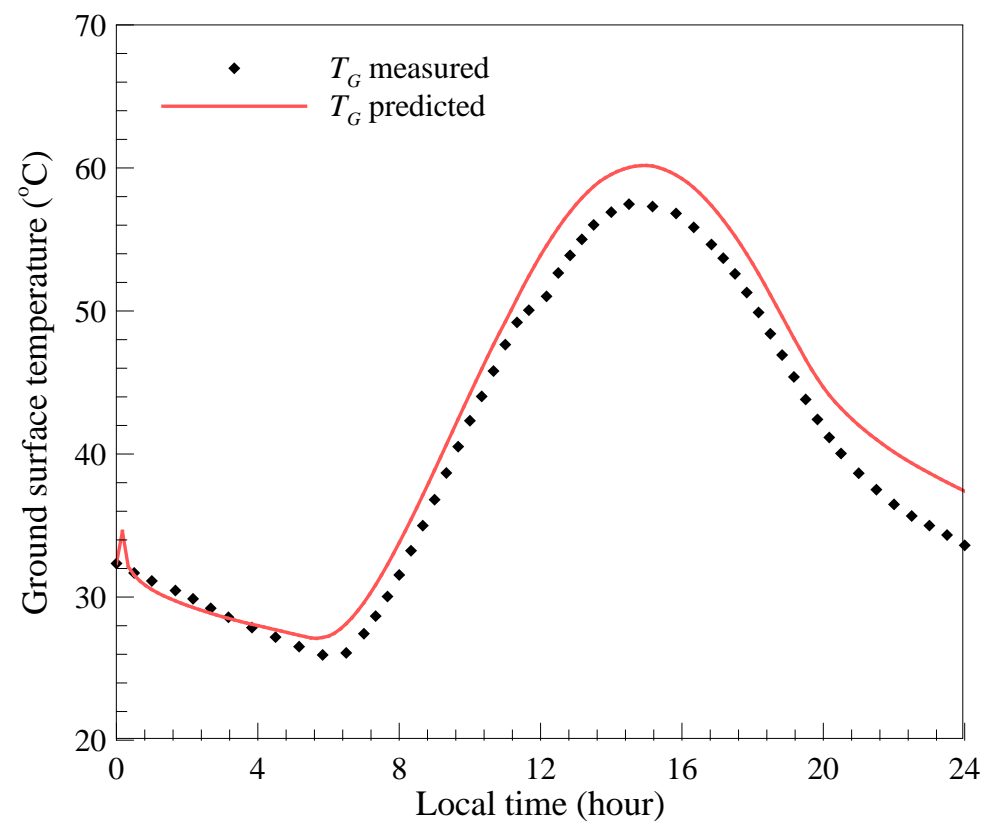

572

573 Figure 8. Model application with (a) radiative forcing measured on 04 June 2012, Phoenix,

574 AZ, and (b) comparison between model prediction and measurement of ground surface

575 temperature. 
(a)

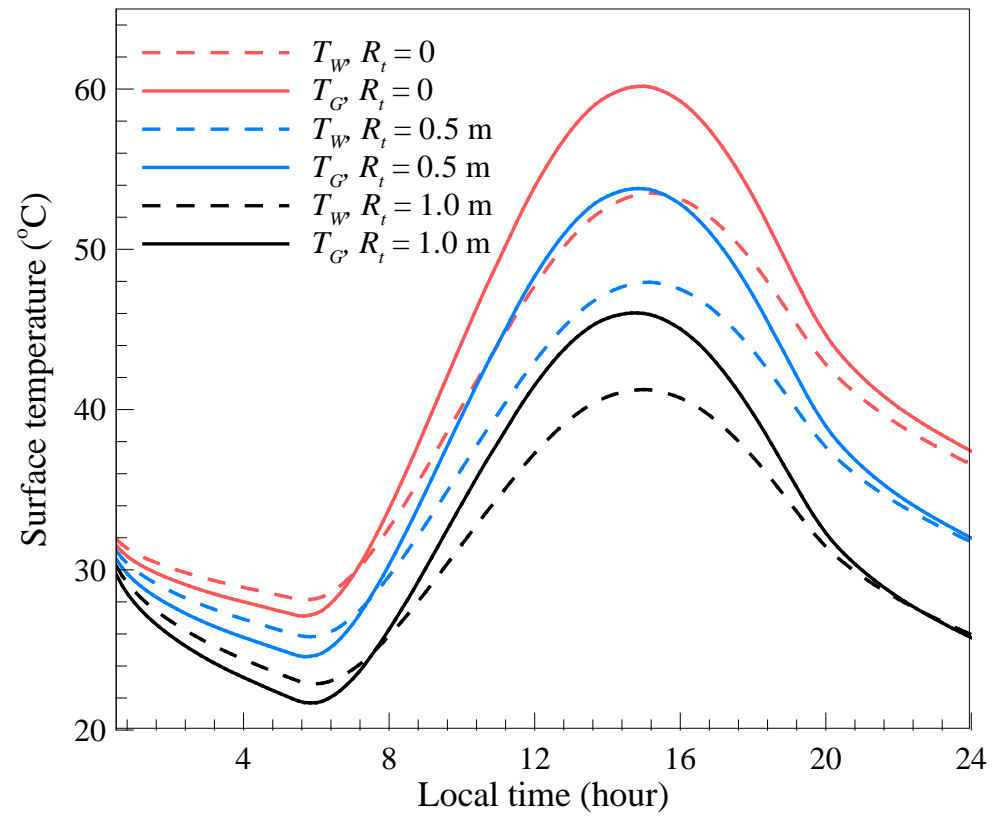

(b)

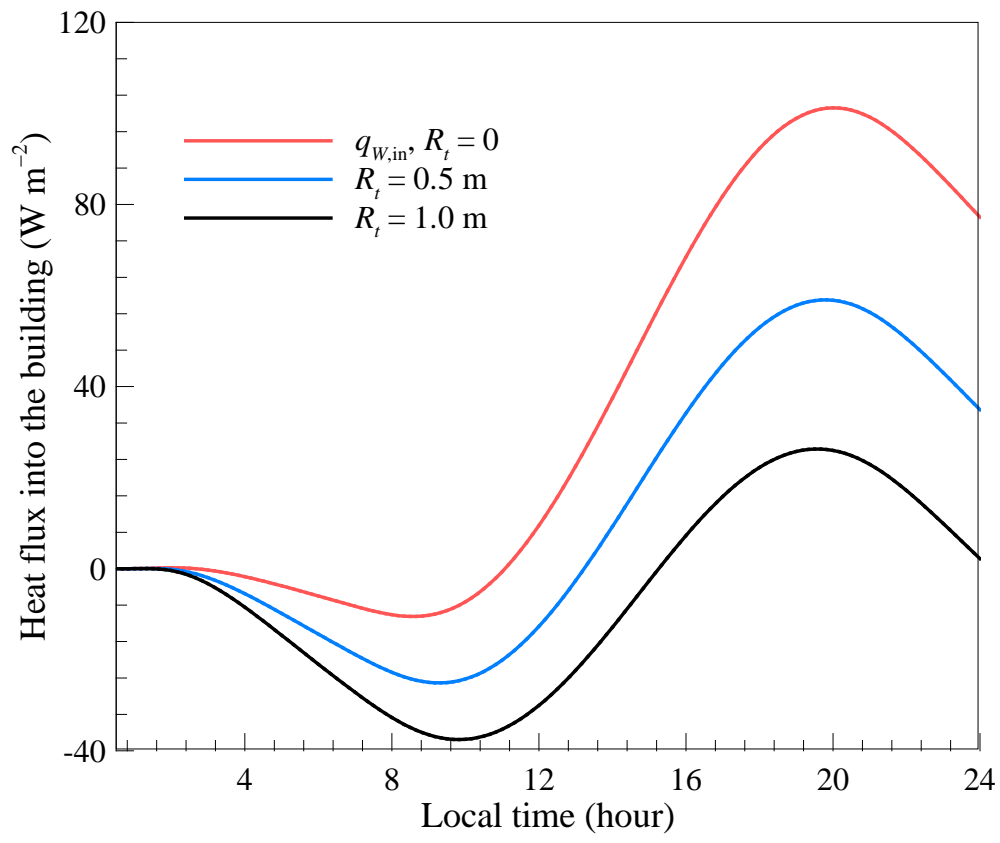

577 Figure 9. Model prediction of diurnal variation of (a) surface temperatures, and (b) heat 578 conducted into building through walls. Diurnal radiative forcing is the same as in Figure 8. 